\title{
Survival and Quality of Hospital Care for Victims of Car Crashes in Western Azerbaijan, Iran
}

\author{
Omid Garkaz ${ }^{1}$, Sahar Paryab², Hamid Reza Mehryar³, Hamid Reza Khalkhali ${ }^{4}$ and Shaker Salari Lak ${ }^{5, *}$ \\ ${ }_{1}^{1}$ MSc in Epidemiology, School of Public Health, Shahroud University of Medical Sciences, Shahroud, Iran \\ 2 Department of Nursing, Ali Abad Katool Branch, Islamic Azad University, Golestan, Iran \\ ${ }^{3}$ Assistant Professor of Emergency Medicine, Urmia University of Medical Sciences, Urmia, Iran \\ 4 Professor of Biostatistics, Urmia University of Medical Sciences, Urmia, Iran \\ ${ }^{5}$ Associate Professor of Epidemiology, Department of Public Health, Tabriz Branch, Islamic Azad University, Tabriz, Iran
}

* Corresponding author: Shaker Salari Lak, Department of Public Health, Tabriz Branch, Islamic Azad University, Tabriz, Iran. Email: salari@iaut.ac.ir, salarilak@yahoo.com

Received 2020 July 30; Revised 2020 August 23; Accepted 2020 August 25.

\begin{abstract}
Background: Car crashes are among the prevalent incidents seriously threatening public health.

Objectives: This study aimed to assess the survival and quality of hospital care for patients of car accidents in Western Azerbaijan, Iran. Methods: This cross-sectional study was conducted on 1,697 trauma victims admitted to Imam Khomeini hospital in Urmia, Iran, during 2016. The data, including systolic pressure, Glasgow Coma Scale, respiratory rate prior to admittance, severity of injuries based on surgery description, limbs and brain computed tomography scan, and diagnostic ultrasound by an specialist, were collected from medical records. The survival chance of patients was estimated using Trauma and Injury Severity Score (TRISS). To evaluate the quality of hospital service, $\mathrm{Z}$ and $\mathrm{W}$ statistics were utilized.

Results: Out of 1,697 admitted victims, 1,226 (72.3\%) and $471(27.7 \%)$ subjects were male and female, respectively. The patients were within the age range of 15-54 years, including 901 (75\%) male and $296(25 \%)$ female subjects. The predominant educational levels were under diploma and illiterate in male and female patients, respectively. The mean values of the Revised Trauma Score for the recovered and deceased patients were $7.75 \pm 0.38$ and $6.19 \pm 1.59$, respectively; however, the mean values of the Injury Severity Score for the recovered and deceased patients were $14.57 \pm 13.72$ and $52.03 \pm 27.02$, respectively, indicating a statistically significant difference between the two groups. The number of observed mortalities was 69; nevertheless, the expected mortalities were 60 cases. Furthermore, the quantified $\mathrm{W}$ and $\mathrm{Z}$ statistics were -9 and 0.02 , respectively.

Conclusion: The results showed that the observed mortality exceeded the expected morality indicating the low quality of hospital care.

Keywords: Car crashes, Iran, TRISS
\end{abstract}

\section{Background}

Human health has been threatened by many hazardous events. Vehicle collision or car crash is one of the pervasive events putting human health at risk. Mortality due to traffic-related injuries is a public health concern in many countries, particularly in lowincome countries (1-3). According to the World Health Organization's annual report, 1.24 million people (18 in every 100,000 individuals) lose their lives due to roadway crashes, and over 50 million individuals are reported with injury or disability. In Asia, car crashes annually cause 400,000 mortalities and over 4 million injuries. The causalities could reach 1.9 million if neglected. Additionally, over $90 \%$ of the mortalities happen in the low-income countries of Africa and Eastern Mediterranean region (4-6).

In Iran, traffic-related injuries are the most prevalent injuries and second cause of mortality (7, 8). In the last decade, the national mortality rate was 30 in every 100,000 vehicles; however, the average rates of the world and Eastern Mediterranean region were 22.6 and 13.9 in 100,000 vehicles, respectively $(9,10)$. In comparison to other countries, the highest mortality rate and burden of disease are accounted for in Iran. The average number of mortalities is 3 per 10,000 vehicles worldwide, which is estimated at 7.3 in Iran (11).

Traffic-related injuries are regarded as predictable events and global major public health challenges. Every day, 30,000 traffic-related injuries and 3,000 mortalities occur around the world. In a study carried out by Soori et al., it was reported that traffic accidents are responsible for $37.5 \%$ of unintentional injuries and the first cause of mortality in the rural areas of Iran (10). As a longstanding key part of pre-hospital triage, the scoring method of traumatic patients has been used to predict early mortality and assist physicians in the patient examination for the provision of proper care. Using the scoring method in pre-admittance proceedings can play an important role in injury mitigation. Improper classification of trauma victims due to the lack of suitable trauma assessment systems could bring irreversible outcomes for patients and might increase the mortality rate $(12,13)$.

The application of survival predictors, such as Trauma and Injury Severity Score (TRISS), Injury Severity Score (ISS), and Revised Trauma Score 
(RTS), for traffic injury victims has currently become a common practice. Using a standard and appropriate treatment, which plays the primary role in the mortality reduction of trauma patients, has become a matter of interest in recent years. Studies have demonstrated that the lack of appropriate treatment is responsible for $50 \%$ of patient mortalities. The presence of well-equipped centers could lead to a $30 \%$ decline in the mortality of trauma patients. The results of a study showed that the presence of equipped centers and their proper measures could reduce the mortality rate from $30 \%$ to $9 \%$. The third phase of mortality in trauma patients occurs within 1-30 days after trauma and approximately $10-20 \%$ of mortalities take place in this period $(14,15)$.

The scoring for the prediction of results can be categorized into three groups of anatomy scores, physiological scores, and combination of the two (16). Survival is the primary purpose of treating severe trauma patients. The secondary purposes include quick recovery, avoiding organ failure, and finally attaining optimal quality of life (15). The Major Trauma Outcome Study (MTOS) was a retrospective study conducted by the American College of Surgeons in 1982 to predict the outcomes of large traumas in several trauma centers (17). To evaluate injury severity and quality of hospital care provided to car accident patients, different systems, such as A Severity Characterization of Trauma, ISS, RTS, and Abbreviated Injury Scale (AIS), are available. The TRISS uses a combination of other systems; therefore, it is more applicable and preferred in developing countries $(18,19)$. The TRISS is one of the credible systems for the assessment of hospital service quality and determination of the expected survival. The TRISS is comprised of three items, namely physiologic score or RTS, anatomic score or ISS, and age $(17,20)$.

In a study carried out by Deshmukh et al. (21) in India, it was observed that the number of mortalities is five cases greater than the results of the MTOS. The studies conducted by Esmaili et al. (22) and Khosravi et al. (23) showed seven and four mortalities higher than the MTOS findings, respectively. All of the aforementioned studies associated the low quality of hospital services with a high number of mortalities (24-26). Although multiple studies investigated traffic-related injuries in Iran, fewer studies were associated with hospital service quality and survival of car accident victims $(15,23)$.

\section{Objectives}

The current study aimed to assess the survival and quality of hospital care in patients with traffic injuries in Eastern Azerbaijan, Iran.

\section{Methods}

This cross-sectional study, with descriptiveanalytical objectives, was conducted using the data of car victims admitted to Imam Khomeini hospital in Urmia, Iran, within January 1 to December 30, 2016. The data were obtained from the patient files in the Medical Records Department of the hospital. The data inclusion criteria were traffic-related injury, at least 3-month of residency in the affiliated cities of Eastern Azerbaijan province before the accident, survival until admittance, registration of the patient data in the hospital trauma system, and diagnosis of at least one injury in the patient. A total of 2,015 individuals were selected based on the inclusion criteria, 1,750 of whom had a history of intensive care unit (ICU) referral, transfer from other cities, and traumas of head, abdomen, and face. Ultimately, out of 1,750 cases, 1,697 patients were available for survival analysis.

The data collection form was comprised of demographic variables (i.e., age, gender, educational level, occupation, and location), traffic accident variables (i.e., location of the accident, patient condition, accident location, transfer to the surgery room, ICU referral, mechanism of injury, and bump on the head), and TRISS indices. Survival prediction systems include TRISS, RTS, and ISS. The ISS is an anatomy score used for the prediction of non-fatal outcomes in patients with several injuries. The RTS physiologic score is utilized for the prediction of postincident mortality. The TRISS is a combination of the RTS, ISS, and age, as a predictor, to assess survival rate after the bump. The TRISS evaluation method is carried out based on the physiologic criteria outlined in Table 1.

The ISS system underwent some modifications since the development. To evaluate the severity of injury using the ISS, the body is divided into six regions, including head and neck, face, chest, abdomen, extremities (e.g., pelvis), and externals (2731). Injuries, based on severity, are ranked on a sixpoint scale (minor, moderate, serious, severe, critical, and maximal). For the calculation of the ISS, the injured organ is initially scored by the AIS. Then,

Table 1. Classification of Revised Trauma Score based on variables

\begin{tabular}{lccc}
\hline Glasgow Coma Scale & Systolic blood pressure & Respiratory rate & Class \\
\hline $\mathbf{3}$ & 0 & 0 & $1-5$ \\
$\mathbf{4 - 5}$ & $1-49$ & $6-9$ & 1 \\
$\mathbf{6 - 8}$ & $50-75$ & 2 & -29 \\
$\mathbf{9 - 1 2}$ & $76-89$ & 3 & $>29$ \\
$\mathbf{1 3 - 1 5}$ & $>89$ & 4 & \\
\hline
\end{tabular}


three injuries with the highest AIS scores are selected. Subsequently, the chosen injuries are squared and summed (ISS $\left.=\mathrm{x}^{2}+\mathrm{y}^{2}+\mathrm{z}^{2}\right)$. The minimum and maximum ISS scores are $3\left(1^{2}+1^{2}+1^{2}\right)$ and $75\left(5^{2}+5^{2}+5^{2}\right)$, respectively. The ISS score ranges from 0 to 75 and increases with the severity of the injury.

The RTS is a physiologic assessment index designed to predict mortality caused by trauma with five independent variables of the Glasgow Coma Scale (GCS), respiratory rate (RR), systolic blood pressure (SBP), chest dilation, and capillary refill. The RTS score is within the range of $0-12$. A low RTS value accounts for higher severity of injury to patients. The RTS scoring system has the highest validity and influence on the prognosis of patients with a concussion $(15,32,33)$. The RTS is also used in triage. Therefore, a logistic regression analysis model was presented to predict the outcome of the injury in patients based on the RTS. In this model, the RTS value is calculated as follows:

(1) $\mathrm{RTS}=0.2908(\mathrm{RR})+0.7326(\mathrm{SBP})+0.9368$ (GCS)

The RTS ranges from 0 to 7.84. Moreover, the RTS value is determined by the inclusion of the three measured indices in the model. Using the RTS, the survival chance of the patients can be measured according to the following formula:

(2) $\mathrm{P}=1 /\left(1+\mathrm{e}^{-\mathrm{RTS}+3 / 5718}\right)$

To assess the probability of survival in patients younger than 15 years, equation 3 is used as follows:

(3) Logit $=-0.4499+0.8085$ (RTS) +0.0835 (ISS) + 1.7430 (age point)

Equation 4 is employed for other age groups. In any condition, the survival percentage is determined based on equation 5 .

(4) Logit $=-2.5355+0.9934$ (RTS) +0.0651 (ISS) + 1.1360 (age point)

(5) $P(S)=1 / 1+e^{\text {logit }}$

The number of expected mortalities in TRISS is determined by the number of patients with an estimated survival chance of $<50 \%$.
To evaluate the quality of hospital services, $\mathrm{Z}$ and $\mathrm{W}$ statistics were measured using the following formulas:

(6) Z-statistic $=\frac{\text { observed death-Expected death }}{\sqrt{\text { Expected death-Expected alive }}}$

(7) $\mathrm{W}-$ statistic $=\frac{\text { Observed alive-Expected alive } \$ 1000}{\text { rate patitents }}$

Then, the obtained findings were compared to the results of the MTOS. A Z-statistic value within the range of $-1.96 /+1.96$ indicated that no significant difference can be observed between the results of the current study and those of the MTOS (34). The TRISS was assessed using an online calculation tool at the trauma website (http://www.trauma.org). The Kolmogorov-Smirnov test was conducted to check the normal distribution of the data. The SPSS software (version 16) was used to analyze the data.

\section{Results}

The results of the present study showed that out of 1,697 hospitalized victims, 1,226 (72.3\%) and 471 $(27.7 \%)$ subjects were male and female, respectively. Both genders were within the age range of 15-54 years, including 901 (75\%) male and 296 (25\%) female patients. The educational levels of the patients were under diploma and illiterate in male and female subjects, respectively. The patients were mostly selfemployed and housewives. Urban areas and streets in particular (Table 2) were the most frequent accident locations among the patients (male: 1,208 [79\%]; female: 314 [21\%]). The majority of the male $(n=366$; $71 \%)$ and female ( $n=286,49 \%)$ victims were pedestrians and passengers, respectively. The most frequent accident locations for males $(n=542 ; 73 \%)$ and females $(n=212 ; 31 \%)$ were in the city and roads between cities, respectively. Most of the patients in both genders were not transferred to the ICU and had blunt trauma and head injury. The majority of male victims underwent surgeries but not the female subjects (Table 3 ).

\begin{tabular}{|c|c|c|c|}
\hline Variable & & $\begin{array}{c}\text { Male frequency } \\
\text { n (\%) }\end{array}$ & $\begin{array}{c}\text { Female frequency } \\
\text { n (\%) }\end{array}$ \\
\hline \multirow{3}{*}{ Age (year) } & $0-14$ & $147(61)$ & $91(39)$ \\
\hline & $15-54$ & $901(75)$ & $296(25)$ \\
\hline & $54<$ & $178(67)$ & $84(33)$ \\
\hline \multirow{5}{*}{ Educational level } & Illiterate & $213(53)$ & $187(47)$ \\
\hline & Under diploma & $608(77)$ & $178(33)$ \\
\hline & Diploma & $294(82)$ & $63(18)$ \\
\hline & Associate's degree & $31(79)$ & $8(21)$ \\
\hline & Bachelor's degree & $80(69)$ & $35(31)$ \\
\hline \multirow{5}{*}{ Occupation } & Unemployed and farmer & $69(97)$ & $2(3)$ \\
\hline & Self-employed and housewife & $592(61)$ & 363 (39) \\
\hline & Retired and student & $61(82)$ & $13(18)$ \\
\hline & Employee and others & $319(93)$ & $23(7)$ \\
\hline & Student and child & $185(66)$ & $94(34)$ \\
\hline \multirow{2}{*}{ Living location } & City & $850(71)$ & 331 (29) \\
\hline & Village & $376(72)$ & 140 (28) \\
\hline Gender & & $1,226(72.3)$ & $471(27.7)$ \\
\hline
\end{tabular}


The observed mortalities were 69 , which were 9 cases higher than the expected deaths $(n=60)$. The $W$ and $\mathrm{Z}$ statistics were reported as 9 and 0.02 , respectively (Figure 1 ).

The GCS level was within the range of $0-3$ in 4 recovered and 20 deceased patients. The maximum RR values in both recovered and deceased groups were within the range of 10-29. The SBP in the recovered and deceased groups was reported as higher than $89 \mathrm{mmHg}$ (Table 4). The mean values of

\begin{tabular}{|c|c|c|c|}
\hline Variable & & $\begin{array}{c}\text { Male frequency } \\
\text { n (\%) }\end{array}$ & $\begin{array}{c}\text { Female frequency } \\
\text { n (\%) }\end{array}$ \\
\hline \multirow{4}{*}{ Accident location } & Highway & $18(77)$ & $4(23)$ \\
\hline & Freeway & $281(66)$ & $139(34)$ \\
\hline & Alley & $21(63)$ & $12(37)$ \\
\hline & Street & $1,208(79)$ & $314(21)$ \\
\hline \multirow{5}{*}{ Position of the injured } & Pedestrian & $366(71)$ & $146(29)$ \\
\hline & Cyclist & $26(92)$ & $2(8)$ \\
\hline & Motorcyclist & $198(96)$ & $8(4)$ \\
\hline & Driver & $327(91)$ & $30(9)$ \\
\hline & Passenger & 307 (51) & 286 (49) \\
\hline \multirow{3}{*}{ Accident location } & In the city & $542(73)$ & $196(27)$ \\
\hline & Between two cities & 479 (69) & $212(31)$ \\
\hline & Village & 205 (77) & $61(33)$ \\
\hline \multirow{2}{*}{ Intensive care unit referral } & Yes & $230(85)$ & $37(15)$ \\
\hline & No & $1,013(71)$ & 412 (29) \\
\hline \multirow{2}{*}{ Surgery room } & Yes & $748(78)$ & $208(22)$ \\
\hline & No & $478(64)$ & $262(36)$ \\
\hline \multirow{2}{*}{ Mechanism of accident } & Penetrating & 113 (77) & $33(23)$ \\
\hline & Blunt & $1,113(71)$ & $438(29)$ \\
\hline \multirow{2}{*}{ Concussion } & Yes & $716(72)$ & $289(28)$ \\
\hline & No & $457(71)$ & $182(29)$ \\
\hline
\end{tabular}

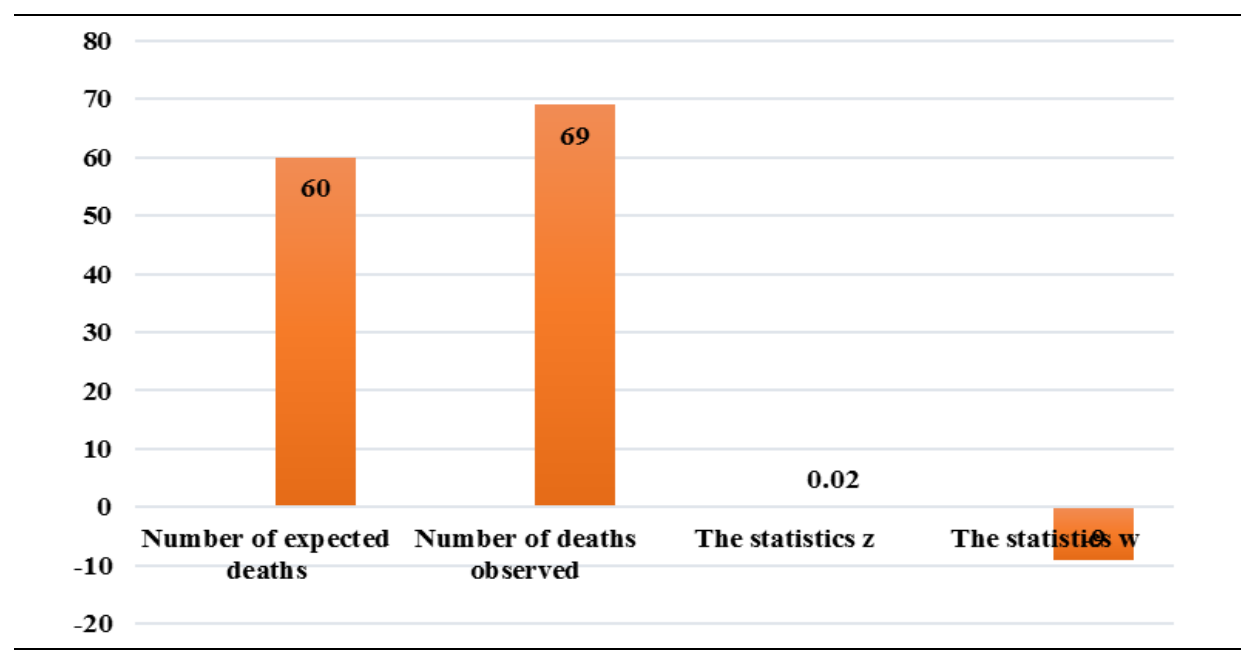

Figure 1. Number of observed and expected mortalities in car crash victims admitted to Imam Khomeini hospital of Urmia, Iran

\begin{tabular}{|c|c|c|c|}
\hline Variable & & $\begin{array}{c}\text { Recovered } \\
\text { n (\%) }\end{array}$ & $\begin{array}{c}\text { Deceased } \\
\text { n (\%) }\end{array}$ \\
\hline \multirow{5}{*}{ Glasgow Coma Scale } & $0-3$ & $4(0.2)$ & $20(29.0)$ \\
\hline & $5-4$ & $7(0.4)$ & $7(10.1)$ \\
\hline & $8-6$ & $24(1.5)$ & $13(18.8)$ \\
\hline & $12-9$ & $36(2.2)$ & $4(5.8)$ \\
\hline & $15-13$ & $1,554(95.5)$ & $25(36.3)$ \\
\hline \multirow{4}{*}{ Respiratory rate } & $1-5$ & $1(0.1)$ & 0 \\
\hline & $9-6$ & $2(0.1)$ & $2(2.9)$ \\
\hline & $10-29$ & $1,619(99.6)$ & $65(94.2)$ \\
\hline & $29<$ & $4(0.2)$ & $2(2.9)$ \\
\hline \multirow{4}{*}{ Systolic blood pressure } & $1-49$ & $7(0.4)$ & 0 \\
\hline & $50-75$ & $2(0.1)$ & $2(2.9)$ \\
\hline & $89-76$ & $21(1.3)$ & $6(8.7)$ \\
\hline & $89<$ & $1,598(98.2)$ & $61(88.4)$ \\
\hline
\end{tabular}




\begin{tabular}{lccc}
\hline \multicolumn{4}{l}{ Table 5. Mean comparison of Trauma and Injury Severity Score quantitative indices in car crash patients } \\
\hline Variable & Recovered & Deceased & P-value \\
\hline Revised Trauma Score & Mean \pm standard deviation & Mean \pm standard deviation & 0.001 \\
Injury Severity Score & $7.75 \pm 0.38$ & $6.19 \pm 1.59$ & 0.001 \\
\hline
\end{tabular}

the RTS in the survived and deceased patients were $7.75 \pm 0.38$ and $6.19 \pm 1.59$, respectively. The mean scores of the ISS in the survived and deceased patients were $14.57 \pm 13.72$ and $52.03 \pm 27.02$, respectively, indicating a statistically significant difference between the recovered and deceased groups (Table 5).

\section{Discussion}

In developed countries, TRISS is used as a qualitative measure to assess the injury and survival chances of trauma patients. The developing countries are no exception in this regard, as some studies were also conducted in such countries (23, 35-37). The findings of the aforementioned studies showed that the observed mortalities were higher than the expected mortalities. Deshmukh et al. (21) estimated expected mortalities at 15\%; however, they reported observed mortalities as $33 \%$. The $\mathrm{W}$-statistic value showed nine mortalities higher than that of the MTOS. Compared to the MTOS value, the Z-statistic value in the present study demonstrated no statistically significant difference between the deceased and recovered patients. It has been noticed that the rate of mortalities caused by accidents was associated with the quality of hospital services. In this regard, the results of the current study are consistent with other investigations $(15,22,23)$. The measured indices explain the role of immediate service provision for the victims and hospital service quality in the survival and recovery of traffic accident patients.

Esmaili et al. (22) quantified the respective $\mathrm{Z}$ and $\mathrm{W}$ statistics of +0.02 and -7 , respectively. In their study, more patients died in comparison to the MTOS, which was explained by poor hospital service quality. In this study, $72.3 \%$ of the patients were male, with the female to male ratio of $1: 4$, which is consistent with the results of studies by Sing et al. (12) and Akbari et al. (38). This might be due to the cultural circumstances constraining women from driving.

Most of the patients in the present survey were within the age range of 15-54 years. It is highlighted that the mortality rate in the elderly, regardless of injury severity, is 2 to 3 times higher than those reported for other age groups. Only $15.4 \%$ of the total patients of this study were older than 55 years (39). This might be due to the population structure of the region, which is predominantly young, and greater involvement of young age groups in traffic-related activities. This finding also demonstrated that young and middle-aged individuals are at high risk of injury or death, thereby indicating the necessity of interventional plans. The educational levels of most male and female patients were under diploma and illiterate, respectively. The patients were mostly included in the category of self-employed and housewife, which is in line with the results of studies conducted by Khorami et al. (40), Khatibi et al. (41), and Ahadi et al. (42).

Esmaili et al. (22) have reported the mean values of ISS as $12.4 \pm 4.3$ and $36.9 \pm 8.9$ in the recovered and deceased patients, respectively. In addition, they calculated the mean values of the RTS at $7.19 \pm 0.93$ and $4.35 \pm 0.74$ in the recovered and deceased subjects, respectively. In the current study, the RTS mean score of the deceased patients was lower than that of the recovered subjects; however, the ISS mean value of the deceased patients was higher than that of the recovered subjects. These results are confirmed by the findings of studies by Chan et al. (43) and Chaudhry et al. (44). Out of 69 deceased patients, 61 individuals had an ISS value of higher than 20. The patients with high ISS scores are at a higher probability of mortality. Moreover, a high ISS score combined with several body injuries, provided that RTS is lower than 5, increases the chance of death in patients. These findings are in line with the findings of studies by Saidi et al. (45), Akhavan Akbari et al. (38), and Paferth et al. (46).

In the MTOS, to determine the severity of the injury, especially in deceased patients, necroscopic methods were applied as accurate techniques for ISS determination. However, the necroscopic data are not available in Iran due to cultural issues generating diagnostic bias, particularly in patients undergoing fewer diagnostic measures as the result of sudden death. To reduce the bias, the patient group was selected from the ICU, Surgery, Neurosurgery, and Orthopedic wards, and those who died in the Emergency Ward were excluded from the study.

In developed countries, most victims with severe and deadly lesions were hospitalized alive due to onsite medical care; nevertheless, in developing countries, most of such patients do not survive to reach the hospital. Therefore, in studies of developing countries, the cases that died in the emergency department were omitted from trauma outcome assessment (47). However, in this regard, the results of a study showed that the implementation of Advanced Trauma Life Support can be significantly effective in the determination of fate and outcome of trauma patients. The emphasis of the aforementioned study was on the immediate on-site treatment of the victims and given the necessity transfer to a trauma 
center. Following this plan, the mortality rate has dropped from $63.3 \%$ to $29.4 \%$ (48).

The majority of the victims were pedestrians in males and passengers in females. This is acknowledged by the findings of studies conducted by Asura et al. (49), Ahadi et al. (42), and Saidi et al. (45). The accidents mostly occurred within the city. Furthermore, $16 \%$ and $56 \%$ of the victims were transferred to specialty wards and surgery rooms, respectively $(45,49,50)$. A large number of patients were injured with blunt trauma and bump on the head $(15,51)$.

One of the strengths of this study was a large sample size in the comprehensive trauma center. Misregistration and incomplete data entry in some records and lack of proper cooperation of some patients were considered the restricting factors in following the survival status. A TRISS study also reflects the quality of hospital services provided for car crash victims. Therefore, it is recommended to carry out periodic surveys to gain knowledge about the quality status of hospital services. If the results of TRISS would be lower than those of the MTOS, the quality of hospital services might require promotion programs, such as educational plans and organization of cardiopulmonary resuscitation and trauma surgery teams.

\section{Conclusion}

In this study, the survival reducing factors included male gender, educational level of under diploma, self-employment and being housewife, urban areas and city streets, being a passenger, blunt trauma, bump on the head, surgery, and low GCS value. Given the TRISS estimate, the hospital care quality in the present study was lower than that reported for the MTOS.

\section{Acknowledgements}

The authors would like to express their gratitude to the Deputy of Research and Technology of Urmia University of Medical Sciences, Urmia, Iran, for financial and administrative support, patients and their families for their cooperation, and medical staff of Imam Khomeini Medical Education Center.

\section{Footnotes}

Authors' Contribution: Omid Garkaz (first author): senior researcher (20\%); Sahar Paryab (second author): discussion of the manuscript (20\%); Hamid Reza Mehryar, (third author): assistant researcher (15\%); Hamid Reza Khalkhali (fourth author): statistical analysis (20\%); Shaker Salari Lak (fifth author): writer of methodology and discussion of the manuscript (25\%)

Conflict of Interests: The authors declare that there is no conflict of interest.

Ethical Approval: This study was extracted from an MSc thesis in Epidemiology by Omid Garkaz with an ethical approval code of IR.UMSU.REC.1396.373 registered in Urmia University of Medical Sciences.

Funding/Support: This study was funded by the Deputy of Research and Technology of Urmia University of Medical Sciences.

\section{References}

1. Papalimperi AH, Athanaselis SA, Mina AD, Papoutsis II, Spiliopoulou CA, Papadodima SA. Incidence of fatalities of road traffic accidents associated with alcohol consumption and the use of psychoactive drugs: a 7-year survey (2011-2017). Exp Ther Med. 2019;18(3):2299-306. doi: 10.3892/etm.2019.7787. [PubMed: 31410180].

2. Peden MM, Puvanachandra P. Looking back on 10 years of global road safety. Int Health. 2019;11(5):327-30. doi: 10.1093/inthealth/ihz042. [PubMed: 31145800].

3. McManus F, Waite P, Shafran R. Cognitive-behavior therapy for low self-esteem: a case example. Cogn Behav Pract. 2009; 16(3):266-75. doi: 10.1016/j.cbpra.2008.12.007.

4. Peden M, Scurfield R, Sleet D, Mohan D, Hyder AA, Jarawan E, et al. World report on road traffic injury prevention. Geneva: World Health Organization; 2004.

5. Mohan D. Analysis of road traffic fatality data for Asia. Proceedings of the Eastern Asia Society for Transportation Studies (The 9th International Conference of Eastern Asia Society for Transportation Studies). Eastern Asia Society for Transportation Studies, South Korea; 2011. doi: 10.11175/ eastpro.2011.0.351.0.

6. Hyder AA, Vecino-Ortiz AI. BRICS: opportunities to improve road safety. Bull World Health Organ. 2014;92(6):423-8. doi: 10.2471/BLT.13.132613. [PubMed: 24940016].

7. Entezami N, Hashemi-Nazari SS, Soori H, Khosravi A, Ghadirzadeh MR. Epidemiology of fatal road traffic accidents in Northern provinces of Iran during 2009 to 2010. Saf Prom Inj Prev. 2015;3(1):1-8.

8. Khademi A, Moradi SE. Statistical study of traffic casualties at Noruz of 2008 in Iran (from 15 march 2008 to 3 April 2008). Sci J Forensic Med. 2009;15(1):21-8.

9. Shojaei A, Moradi S, Alaeddini F, Khodadoost M, Ghadirzadeh MR, Khademi A. The association between completed suicides and season of the year in an Iranian population. Iran J Public Health. 2013;42(3):293-7. [PubMed: 23641406].

10. Soori H, Ainy E, Iranfar M. Road traffic status in the world and Iran: review of results from the World Health Organization. $J$ Saf Prom Inj Prev. 2013;1(2):53-62.

11. Ainy E, Soori H, Ganjali M, Le H, Baghfalaki T. Estimating cost of road traffic injuries in Iran using willingness to pay (WTP) method. PLoS One. 2014;9(12):e112721. doi: 10.1371/journal. pone.0112721. [PubMed: 25438150].

12. Singh J, Gupta G, Garg R, Gupta A. Evaluation of trauma and prediction of outcome using TRISS method. J Emerg Trauma Shock. 2011;4(4):446-9. doi: 10.4103/0974-2700.86626. [PubMed: 22090735].

13. Varghese M. Prehospital trauma care evolution, practice and controversies: need for a review. Int J Inj Contr Saf Promot. 2020;27(1):69-82. doi: 10.1080/17457300.2019.1708409. [PubMed: 31984859].

14. Watts HF, Kerem Y, Kulstad EB. Evaluation of the revised trauma and injury severity scores in elderly trauma patients. $J$ Emerg Trauma Shock. 2012;5(2):131-4. doi: 10.4103/09742700.96481. [PubMed: 22787342].

15. Norouzi V, Feizi I, Vatankhah S, Pourshaikhian M. Calculation of the probability of survival for trauma patients based on trauma score and the injury severity score model in fatemi hospital in ardabil. Arch Trauma Res. 2013;2(1):30-5. doi: 10.5812/atr.9411. [PubMed: 24396787].

16. Wright JH, Brown GK, Thase ME, Basco MR. Learning cognitive- 
behavior therapy: an illustrated guide. New York: American Psychiatric Pub; 2017.

17. Boyd CR, Tolson MA, Copes WS. Evaluating trauma care: the TRISS method. Trauma score and the injury severity score. $J$ Trauma. 1987;27(4):370-8. [PubMed: 3106646].

18. Moore EE, Moore FA. American association for the surgery of trauma organ injury scaling: 50th anniversary review article of the Journal of Trauma. J Trauma. 2010;69(6):1600-1. doi: 10.1097/TA.0b013e318201124e. [PubMed: 21150537].

19. Baker SP, o'Neill B, Haddon Jr W, Long WB. The injury severity score: a method for describing patients with multiple injuries and evaluating emergency care. J Trauma. 1974;14(3):187-96. [PubMed: 4814394].

20. Baker SP, O'neill B. The injury severity score: an update. J Trauma. 1976;16(11):882-5. doi: 10.1097/00005373197611000-00006. [PubMed: 994270].

21. Deshmukh VU, Ketkar MN, Bharucha EK. Analysis of trauma outcome using the TRISS method at a tertiary care centre in Pune. Indian J Surg. 2012;74(6):440-4. doi: 10.1007/s12262011-0404-5. [PubMed: 24293896].

22. Esmaeili ED, Sadeghi-Bazargani H, Vahdati SS, Shokouhi G, Safaiyan A, Lak SS. Assessment of survival and hospital care quality in patients with traffic injury in east Azerbaijan. Trauma Mon. 2017;22(5):e35303. doi: 10.5812/traumamon.35303.

23. Khosravi AH, Ebrahimi HO. To evaluate the outcomes of patients with truma admitted to the imam hossein hospital, shahrood using the trauma and injury severity score (TRISS). Iran J Epidemiol. 2008;4(2):35-41.

24. Davoodi F, Hashemi-Nazari SS, Ghadirzadeh MR. An epidemiology study of road traffic accidents resulting in death: in Lorestan province in 2012. Safety Promot Inj Prev. 2016;3(4):257-62.

25. Rodríguez JM, Peñaloza RE, Montoya JM. Road traffic injury trends in the city of Valledupar, Colombia. A time series study from 2008 to 2012. PLoS One. 2015;10(12):e0144002. doi: 10.1371/journal.pone.0144002. [PubMed: 26657887].

26. Macinko J, Mullachery P, Silver D, Jimenez G, Neto OL. Patterns of alcohol consumption and related behaviors in Brazil: evidence from the 2013 National Health Survey (PNS 2013). PLoS One. 2015;10(7):e0134153. doi: 10.1371/journal.pone. 0134153. [PubMed: 26230389].

27. Baker CC, Oppenheimer L, Stephens B, Lewis FR, Trunkey DD. Epidemiology of trauma deaths. Am J Surg. 1980;140(1):14450. doi: 10.1016/0002-9610(80)90431-6. [PubMed: 7396078].

28. Tirtayasa PM, Philippi B. Prediction of mortality rate of trauma patients in emergency room at Cipto Mangunkusumo Hospital by several scoring systems. Med J Indonesia. 2013;22(4):22731. doi: $10.13181 /$ mji.v22i4.603.

29. Ghadirzadeh M, Shojaei A, Khademi A, Khodadoost M, Kandi M, Alaeddini $\mathrm{F}$, et al. Status and trend of deaths due to traffic accidents from 2001 to 2010 in Iran. Iran J Epidemiol. 2015;11(2):13-22.

30. Masoumi K, Forouzan A, Barzegari H, Darian AA, Rahim F, Zohrevandi B, et al. Effective factors in severity of traffic accident-related traumas; an epidemiologic study based on the Haddon matrix. Emergency. 2016;4(2):78-82. [PubMed: 27274517].

31. Xiong L, Zhu Y, Li L. Risk factors for motorcycle-related severe injuries in a medium-sized city in China. AIMS Public Health. 2016;3(4):907-22. doi: 10.3934/publichealth.2016.4.907. [PubMed: 29546203].

32. Vernon DD, Furnival RA, Hansen KW, Diller EM, Bolte RG, Johnson DG, et al. Effect of a pediatric trauma response team on emergency department treatment time and mortality of pediatric trauma victims. Pediatrics. 1999;103(1):20-4. doi: 10.1542/peds.103.1.20. [PubMed: 9917434].

33. Fani-Salek MH, Totten VY, Terezakis SA. Trauma scoring systems explained. Emerg Med. 1999;11(3):155-66. doi: 10.1046/j.1442-2026.1999.00039.x.

34. Hariharan S, Chen D, Parker K, Figari A, Lessey G, Absolom D, et al. Evaluation of trauma care applying TRISS methodology in a
Caribbean developing country. J Emerg Med. 2009;37(1):85-90. doi: 10.1016/j.jemermed.2007.09.051. [PubMed: 18584995].

35. Mohyuddin GR, Alam Z, Malik UZ, Shakil O, Haq AU. Revised trauma score as a predictor of outcome in trauma cases: experiences at a tertiary care hospital in Karachi, Pakistan. $J$ Ayub Med Coll Abbottabad. 2015;27(3):584-6. [PubMed: 26721013].

36. Hasnani R, Arshad SZ, Zafar H. Prediction model for survival of trauma patients. J Independ Stud Res. 2012;10(1):24.

37. Madar R, Adini B, Greenberg D, Waisman Y, Goldberg A. Perspectives of health professionals on the best care settings for pediatric trauma casualties: a qualitative study. Isr J Health Policy Res. 2018;7(1):12. doi: 10.1186/s13584-018-0207-2. [PubMed: 29587869].

38. Akbari GA, Mohammadian A. Comparison of the RTS and ISS scores on prediction of survival chances in multiple trauma patients. Acta Chir Orthop Traumatol Cech. 2012;79(6):535-9. [PubMed: 23286687].

39. Pathak S, Jindal A, Verma A, Mahen A. An epidemiological study of road traffic accident cases admitted in a tertiary care hospital. Med J Armed Forces India. 2014;70(1):32-5. doi: 10.1016/j.mjafi.2013.04.012. [PubMed: 24623944].

40. Khorrami Z, Nazari SS, Ghadirzadeh MR. An epidemiology study of deaths from road traffic accidents. Saf Promot Inj Prev. 2017;4(4):217-24.

41. Khatibi SR, Dinpanah H, Maajani K, Khodadost M, Khodadost B, Kakhki S, et al. The burden of road traffic injuries in the northeast of Iran: the result of a population-based registry. J Inj Violence Res. 2020;12(1):63-72. doi: 10.5249/jivr.v12i1.1265. [PubMed: 31849366].

42. Ahadi M, Moghadam GF. Analysis of accident data within the city and provide solutions to reduce losses. Transp Technol. 2012;7(19):25-32.

43. Chan CKO, Yau KK, Cheung MT. Trauma survival prediction in Asian population: a modification of TRISS to improve accuracy. Emerg Med J. 2014;31(2):126-33. doi: 10.1136/emermed2012-201831. [PubMed: 23314210].

44. Chaudhry N, Naqi SA, Qureshi AU. Effectiveness of TRISS to evaluate trauma care in a developing country. Emerg Med. 2012;2(124):2-7. doi: 10.4172/2165-7548.1000124.

45. Saidi H, Mutiso BK, Ogengo J. Mortality after road traffic crashes in a system with limited trauma data capability. $J$ Trauma Manag Outcomes. 2014;8(1):4. doi: 10.1186/17522897-8-4. [PubMed: 24524582].

46. Paffrath T, Lefering R, Flohé S, TraumaRegister DGU. How to define severely injured patients?--an Injury Severity Score (ISS) based approach alone is not sufficient. Injury. 2014;45(Suppl 3):S64-9. doi: 10.1016/j.injury.2014.08.020. [PubMed: 25284238].

47. Hashmi ZG, Haider AH, Zafar SN, Kisat M, Moosa A, Siddiqui F, et al. Hospital-based trauma quality improvement initiatives: first step toward improving trauma outcomes in the developing world. J Trauma Acute Care Surg. 2013;75(1):60-8. doi: 10.1097/TA.0b013e31829880a0. [PubMed: 23778440].

48. van Olden GD, Meeuwis JD, Bolhuis HW, Boxma H, Goris RJA. Clinical impact of advanced trauma life support. Am J Emerg Med. 2004;22(7):522-5. doi: 10.1016/j.ajem.2004.08.013. [PubMed: 15666253].

49. Osoro M, Ng Z, Oundo J, Omolo J, Luman E. Factors associated with severity of road traffic injuries, Thika, Kenya. Pan Afr Med J. 2011;8(1):20. doi: 10.4314/pamj.v8i1.71076. [PubMed: 22121429].

50. Mazandarani PD, Heydari K, Hatamabadi H, Kashani P, Danesh YJ. Acute physiology and chronic health evaluation (APACHE) III score compared to trauma-injury severity score (TRISS) in predicting mortality of trauma patients. Emergency. 2016; 4(2):88. [PubMed: 27274519].

51. Lotfi MH, Montazer M, Lashkardoost H, Shamsi F, Askari M, Hamedi E, et al. Road traffic accidents in Yazd province, Iran: a longitudinal study (2012-2016). Arch Trauma Res. 2018; 7(2):68-72. doi: 10.4103/atr.atr_9_18. 